\title{
Parâmetros Estruturais de uma Área de Macrodrenagem em Belém, Estado do Pará
}

\author{
Structural Paramenters of a Macro Drainage Area in Belém, state of Para \\ Parámetros estructurales de un área de macro-drenaje en Belém, Estado de Pará
}

Recebido: 31/05/2021 | Revisado: 07/06/2021 | Aceito: 11/06/2021 | Publicado: 26/06/2021

\author{
Jessivaldo Rodrigues Galvão \\ ORCID: https://orcid.org/0000-0001-6454-7556 \\ Universidade Federal Rural da Amazônia, Brasil \\ E-mail: jessigalvao50@gmail.com \\ Valdeci Junior Fonseca Pinheiro \\ ORCID: https://orcid.org/0000-0002-7190-8265 \\ Universidade Federal Rural da Amazônia, Brasil \\ E-mail: valdecijr04091997@gmail.com \\ Leonardo de Almeida Oliveira \\ ORCID: https://orcid.org/0000-0002-5195-6622 \\ Universidade Federal Rural da Amazônia, Brasil \\ E-mail: leonardoaalooliveira@gmail.com \\ Mateus Augusto de Carvalho Santana \\ ORCID: https://orcid.org/0000-0002-4982-7311 \\ Universidade Federal Rural da Amazônia, Brasil \\ E-mail:ma1041578@gmail.com \\ Yuri Pereira Mussio \\ ORCID: https://orcid.org/0000-0002-5332-4274 \\ Universidade Federal Rural da Amazônia, Brasil \\ E-mail: mussioyuri@gmail.com
}

\begin{abstract}
Resumo
A estrutura de uma comunidade vegetal é importante para o entendimento do ecossistema florestal, garantindo o seu uso sustentável. Objetivou-se neste trabalho caracterizar a composição vegetal do Parque ecológico de Belém e perdas inerentes a essas tipologias devido as alterações antrópicas. A área de estudo localiza-se em Belém, com 44,06 ha de extensão. Os parâmetros calculados foram o índice de valor de importância, regeneração natural, categoria de tamanho, posição sociológica e valor de importância ampliado. Nas áreas às margens do canal e nas adjacencias, houve equilíbrio nos valores de VIFs para as Famílias mais importantes Clusiaceae, Arecaceae e Fabaceae. Importante destacar, na Área do entorno, as famílias Arecaceae, Fabaceae, Clusiaceae e Caesalpiniaceae. Caraipa grandiflora e Mauritia carana apresentaram maiores valores de IVIr\% nas áreas avaliadas. Espécies que ganharam importância foram as que objetivaram maiores valores de posição sociológica e regeneração natural e as que perderam, mesmo possuindo representantes nos estratos intermediário e superior, não apresentaram regeneração natural.
\end{abstract}

Palavras-chave: Macrodrenagem; Fitossociologia; Área urbana; Várzea; Preservação.

\begin{abstract}
The structure of a plant community is important for understanding the forest ecosystem, ensuring its sustainable use. The objective of this work was to characterize the Park's plant composition and losses inherent to these types due to anthropic changes. The study area is located in Belém, with 44.06 ha in length. The caculated parameters were the importance value index, natural regereneration, size category, sociological position and expanded importance value. In areas A1 and A2, there was a balance in the values of VIFs for the most important families Clusiaceae, Arecaceae and Fabaceae. It is important to highlight, in Area A3, the families Arecaceae, Fabaceae, Clusiaceae and Caesalpiniaceae. Caraipa grandiflora and Mauritia carana presented higher values of IVIr\% in the evaluated areas. Species that gained importance were those that obtained higher values of sociological position and natural regeneration and those that lost, even having representatives in the middle and upper strata, did not show natural regeneration.
\end{abstract}

Keywords: Macrodrainege; Phytosociology; Urban area; Lowland; Preservation.

\section{Resumen}

La estructura de una comunidad vegetal es importante para comprender el ecosistema forestal y garantizar su uso sostenible. El objetivo de este trabajo fue caracterizar la composición vegetal del Parque Ecológico de Belém y las pérdidas inherentes a estas tipologías por alteraciones antrópicas. El área de estudio está ubicada en Belém, con una superficie de 44,06 ha. Los parámetros calculados fueron el índice de valor de importancia, la regeneración natural, la categoría de tamaño, la posición sociológica y el valor de importancia extendida. En las áreas de los márgenes del 
canal y adyacentes a él, hubo un equilibrio en los valores de VIF para las familias más importantes Clusiaceae, Arecaceae y Fabaceae. Es importante destacar, en los alrededores, las familias Arecaceae, Fabaceae, Clusiaceae y Caesalpiniaceae. Caraipa grandiflora y Mauritia carana mostraron valores más altos de IVIr\% en las áreas evaluadas. Las especies que ganaron importancia fueron aquellas que apuntaban a valores más altos de posición sociológica y regeneración natural, y las que perdieron, aun teniendo representantes en los estratos intermedios y superiores, no presentaron regeneración natural.

Palabras clave: Macrodrenaje; Fitosociología; Área urbana; Bosque Inundado; Preservación.

\section{Introduçãa}

Nas cidades brasileiras verifica-se intensos processos de expansão e transformação desde meados de 1960, principalmente em suas estruturas urbanas, com consideráveis mudanças na paisagem (Dias et al., 2020). Com a diminuição da cobertura vegetal, que é caracterizada como o elemento mais vulnerável do cenário urbano (Albuquerque \& Molinari, 2020), natural na Região Metropolitana de Belém vem acontecendo em ritmo acelerado em especial nas regiões periféricas.

Os recursos naturais também são encontrados em áreas verdes, vislumbradas como espaços nos quais há o predomínio de vegetação arbórea, incluindo as praças, os jardins públicos e os parques urbanos (Resolução CONAMA N³69/2006). O progresso das técnicas de ocupação dos espaços urbanos desencadeou em alterações consideráveis nessa paisagem, para além de favorecer fatos como alagamentos e inundações (Moura et al., 2020). Com isso, torna-se imprescindível o Projeto de Macrodrenagem da Bacia do Una levado a efeito pelo Governo do Estado do Pará e o Município de Belém, através da Companhia de Saneamento do Estado do Pará (COSANPA) para o saneamento de maior parte da cidade.

Por outro lado, as obras de alargamento e dragagem propiciarão melhoras na qualidade de vida das populações beneficiadas, uma vez que em 2017 o Instituto Brasileiro de Geografia e Estatística (IBGE, 2017), disponibilizou um estudo no qual examinou que $76 \%$ dos habitantes urbanos brasileiros não tem qualidade de vida.

O desflorestamento para atender a escassez das obras não apenas afetou as áreas legalmente conservadas assim com aquelas ditas "Institucionais" ligados ao Ministério da Marinha e a Companhia das Docas do Pará (CDP), espaços verdes conservados mostram resultados relevantes no que diz respeito à ótica de saúde da população (Dias et al., 2020). Na área da CDP grande parte do desflorestamento foi atribuída à construção de um conjunto residencial necessário ao remanejamento da população atingida chamado de PROMORAR.

A urbanização é vislumbrada como umas das principais fontes de degradação (Sene et al., 2020). No Parque Ecológico do Município de Belém (P. E. M. B.), local da realização dos estudos, teve sua área hoje preservada graças às atuações conservacionistas da Associação dos Moradores do Conjunto Médici II (AMME), que conquistou por vezes impossibilidade que a área fosse invadida, sendo essas ações adiante que resultaram no seu tombamento como Parque.

Correspondente a vários fatores como a ausência de fiscalização e até ligados a fatores culturais relativos ao uso dos recursos naturais como coleta de frutos com o açaí, a área do Parque vem desafiando diversos processos antrópicos por parte da população do entorno tais como a remoção de madeira, a caça e pesca ilegal, a preocupação com os recursos naturais tem ganhado cada vez mais notoriedade (Degrande et al., 2020).

A estrutura de uma comunidade vegetal é importante para o entendimento do ecossistema florestal e, vislumbrando a interação ser-humano e natureza, precisa ser sensível a funcionalidade dessas comunidades de forma sutil, elaborada e planejada (Alencar \& Cardoso, 2015). A atenção com as áreas verdes em ambientes verdes se fundamenta devido sua colaboração para a melhoria da qualidade ambiental em espaços urbanos, mediante as funções socias, ecológicas, históricas, estéticas e educativas que são aptas a desempenhar (Campos \& Castro, 2017).

Com isso, o intuito do presente trabalho vislumbra a caracterização da composição florística da vegetação do Parque, bem como as perdas inerentes a essas tipologias; além de fazer avaliação do grau de alteração na florística do povoamento adulto e da regeneração natural em áreas a ser desmatada, nas áreas do entorno traduzidos pelos índices de diversidade e 
similaridade florística.

\section{Metodologia}

Localizado na Região Metropolitana de Belém a $1^{\circ} 28^{\prime} \mathrm{S}$ e $18^{\circ} 27^{\prime} \mathrm{W}$, a área que foi realizada o estudo levou em consideração uma área totalizando 44, 06 ha (Figura 1).

Figura 1. Espaço geográfico em que se localiza o Parque Ecológico do Município de Belém (P.E.M.B.).

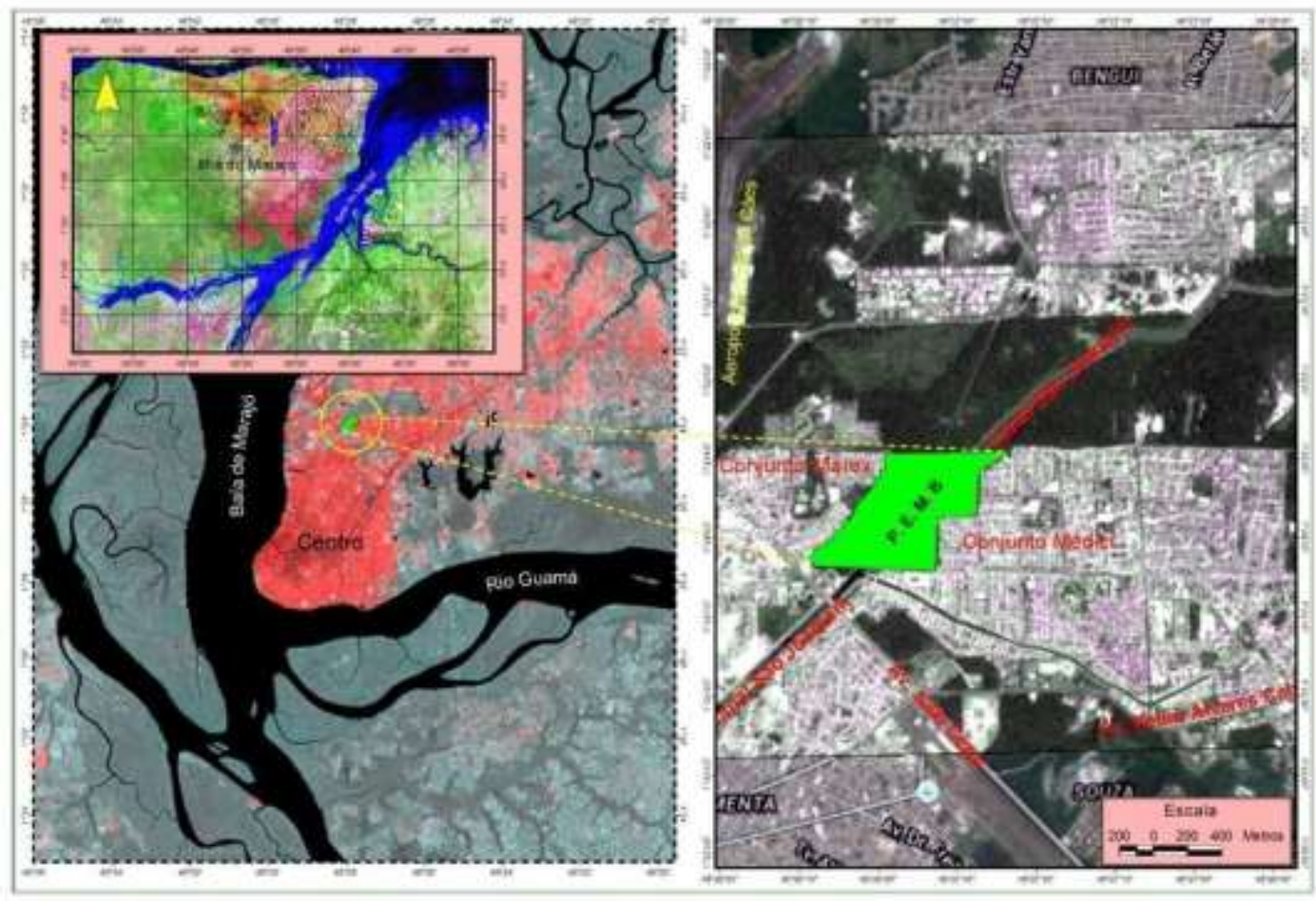

Fonte: Autores.

Esse espaço do Parque Ecológico do Município de Belém (P.E.M.B.) legalmente expõe apenas 33,30ha (Lei Municipal $\mathrm{N}^{\circ} 7.553$ de 19 de novembro de 1991). A remanescente da área 10,76 ha, embora não estarem até esse momento legalmente tombadas por demandas de ordens formais, também foi incluída no estudo. Vislumbra-se o clima como de tropical chuvoso (Barbosa et al., 2015).

Os solos apresentam a textura média, com aspectos próprias de solos de várzea. O seguimento sedimentar é basicamente argiloso, determinando uma "planície de lama", onde os solos são descritos como glaissolos álicos, como na maior parte da área, ou como glaissolos eutróficos, definidos nas margens de alguns igarapés, (Embrapa, 2018).

Para a efetuação do inventário florestal, utilizou-se fita métrica, prancheta, fichas de campo e câmera fotográfica, bem como, prensa e sacos plásticos para coleta de exsicatas. Para facilitar o acesso as margens foram empregues botes e jangadas.

Por meio do Sistema Geográfico de informações (SGI) a área de trabalho foi digitalizada, no laboratório da Superintendência de Desenvolvimento da Amazônia — SUDAM, no decorrer da realização do Estudo de Diagnóstico Ambiental (Projeto UNA).

A organização horizontal e vertical da vegetação foi descrita por meio do método de amostragem sistemática. Foram distribuídas as unidades de amostras uniformemente na área, o que possibilitou um reconhecimento mais pormenorizado, sendo de grande contribuição para a identificação e definição do mapa de vegetação. 
Foram dispostos os transectos ao longo do canal e equidistantes a cada 40m, na orientação Leste/Oeste a partir de uma diretriz Norte/Sul que separou a vegetação em dois grandes fragmentos: a margem direita (lado oeste do canal) e esquerda (lado Leste do canal). As duas margens foram identificadas através das amostras as áreas contíguas ao canal e as áreas adjacentes. Essa identificação foi necessária uma vez que as áreas ditas contíguas serão aquelas retiradas quando da dragagem do canal. Já as áreas adjacentes, retratam a vegetação remanescente propriamente dita. E por fim as áreas classificadas como do entorno aqui descritas como mata da Marinha.

Depois da coleta de dados do levantamento florístico, foi realizado o cruzamento da base cartográfica IBGE 1: 50.000 e pontos da carta topográfica 1:5.000 para plotar a disposição planimétrica das cotas do terreno.

Utilizaram-se parcelas amostrais de $10 \mathrm{~m} \times 15 \mathrm{~m}(150 \mathrm{~m} 2)$ que foram assim distribuídas: um total de 49 parcelas para as áreas contigua (A1- canal), 65 parcelas para áreas adjacentes (A2 - adjacentes) e 13 para áreas do entorno (A3), que totalizaram $7.350 \mathrm{~m} 2,9.750 \mathrm{~m} 2$ e $1.950 \mathrm{~m} 2$ respectivamente, representando 4,31\% de incidência amostral.

Nas parcelas, delimitou-se a área através de trena e procedeu-se a enumeração de $100 \%$ dos indivíduos com Circunferência à Altura do Peito equivalendo em média $2 \mathrm{~m}$ já descontando as sapopemas, e $(\mathrm{CAP} \geq 15 \mathrm{~cm})$ sendo a altura comercial, estimada com vara de 5m. Para possibilitar melhor compreensão das comunidades foram considerados dois níveis de abordagens. No nível 1, foram abordados os indivíduos com $15 \leq \mathrm{CAP}<30 \mathrm{~cm}$, classificados como pertencentes a regeneração natural.

As coletas foram realizadas de maio a setembro, período em que foram processadas as exsicatas do material fértil das espécies. As exsicatas foram referenciadas junto ao Herbário do Museu Emílio Goeldi. O sistema adotado para a classificação do material foi o de Cronquist (1981).

Para a determinação da área mínima representativa e do tamanho das parcelas, considerando que as áreas apresentam vegetação em estádio sucessional relativamente uniforme, utilizou-se a curva espécie-área (Matteucci \& Colma, 1982). O método adotado indica que é possível obter-se um tamanho ideal para uma boa amostragem na medida em que se aumenta o tamanho da unidade da amostra. Nas primeiras amostras ocorre um aumento brusco do número de espécies até que chegando a determinado ponto, o acréscimo de novas espécies começa a ser muito baixo ou nulo. Quantos as análises fitossociológica, estas foram feitas utilizando-se o programa Fitopac.

O índice de valor de importância (IVI) fornece uma ideia abrangente da estrutura das comunidades, caracterizando a importância de cada espécie para o conjunto total do povoamento (Lamprecht,1964). Esse parâmetro é estimado através da combinação dos valores relativos da participação de cada espécie (Matteucci \& Colma, 1982). Tais parâmetros quando reunidos numa única expressão, permitem a hierarquização das espécies, dada pela somatória dos valores da frequência, abundância e dominância.

Oliveira (1997) chamou o IVI de VIE para melhor caracterizar a importância da espécie na comunidade. Também se utilizou de um descritor que denominou de composto para indicar a importância da família na comunidade, levando em conta os parâmetros relativos de densidade, dominância e diversidade (DIV), sendo este último expresso pelo número de espécies da família sobre o total das espécies da amostra. Neste estudo, adotou-se o procedimento descrito por Oliveira (1997), ou seja:

\section{VIEi $=$ Fri + DMri + Dri \\ VIFf $=$ Drf + DMrf + DIVf}

Onde:

VIEi = Valor de importância da espécie na comunidade;

VIFf = Valor de importância da família;

Fri $=$ Frequência relativa da i-ésima espécie, em \%; 
Dri $=$ Densidade relativa da i-ésima espécie, em \%;

DMri = Dominância relativa da i-ésima espécie; em \%;

DIVf $=$ Diversidade;

Drf $=$ Densidade relativa da família (porcentagem do número de árvores

Pertencentes a Família em relação ao total de indivíduos); e

DMrf = Dominância relativa da família (porcentagem da área Basal da Família em relação ao total da população).

Para o estudo da estrutura do povoamento além da estrutura horizontal, utilizou-se a metodologia proposta por Finol (1971) e aplicada por Carvalho (1982) e Jardim (1986/87), que inclui dois novos parâmetros: a Regeneração natural e a Posição sociológica.

A regeneração natural foi incorporada à análise estrutural através de cálculos da Abundância, Frequência e Categoria de tamanho em valores absolutos e relativos das espécies. Os valores de abundância e frequência foram obtidos pelo mesmo procedimento utilizado na estrutura horizontal, abordados anteriormente.

Neste estudo considerou-se a regeneração natural como sendo todos indivíduos pertencentes a classe $15 \leq \mathrm{CAP}<$ $30 \mathrm{~cm}$ em apenas um nível de abordagem (Tabela 1).

O valor da regeneração natural relativa (RN\%) para cada espécie foi obtido pela média aritmética dos valores relativos da abundância, frequência e categoria de tamanho.

\section{$\mathrm{RGr} \% \mathrm{ij}=(\mathrm{ABr}+\mathrm{FRr}+\mathrm{CTr}) / 3$}

Onde:

$\mathrm{RGr}=$ Regeneração natural relativa;

$\mathrm{ABr}=$ Abundância relativa;

$\mathrm{FRr}=$ Frequência relativa; e

$\mathrm{CTr}=$ Categoria de tamanho relativa.

Para estimar o parâmetro Categoria de tamanho absoluta da regeneração natural (CTabsRN) e Categoria de tamanho relativa da regeneração natural (CTreIRN) usam-se os critérios sugeridos por Finol (1970) e Longhi (1980) e modificados por Carvalho (1982). Segundo Jardim (1986/87) para calcular a posição sociológica das espécies da comunidade é necessário estratificar a floresta atribuindo valores numéricos aos estratos. Neste estudo adotou-se o mesmo critério sugerido para o número de estratos.

\section{CTabs RN = [(nI x NI + n II x NII + nII x NIII $)] /$ N \\ CTrelRN $=\left(\right.$ CTabs RN $/ \sum$ CTabs RN $) \times 100$}

Onde:

CTrelRN = Categoria de tamanho relativa da regeneração natural;

CTabsRN = Categoria de tamanho absoluta da regeneração natural;

nI, nII, nIII = Número de indivíduos de cada espécie nas classes de tamanho I;

NI, NII, NIII = Número total de indivíduos na classe I, II e II;

$\mathrm{N}=$ Número total de indivíduos da regeneração natural. 
Tabela 1. Estratificação da vegetação por classes de $(\mathrm{CAP} \geq 15 \mathrm{~cm})$ Circunferência a Altura do Peito considerando os níveis de abordagem da população na área do P.E.M.B.

\begin{tabular}{cccc}
\hline Tamanho da Vegetação & Classe de CAP $(\mathbf{c m})$ & NAP & Estrato \\
\hline RG & $15-19,9$ & I & CT1 \\
\hline RG & $20-24,9$ & I & CT2 \\
\hline RG & $25-29,9$ & I & CT3 \\
\hline PA & $30-34,9$ & II & If \\
\hline PA & $35-44,9$ & II & If \\
\hline PA & $45-49,9$ & II & Md \\
\hline PA & $50-54,9$ & II & Md \\
\hline PA & $55-59,9$ & II & Sp \\
\hline PA & $60-64,9$ & II & Sp \\
\hline PA & $65-69,9$ & II & Sp \\
\hline PA & $70-74,9$ & II & Sp \\
\hline PA & $<75$ & II & Sp
\end{tabular}

RG - Regeneração; NAP - Nível de abordagem da população; If - Estrato inferior; Md - Estrato médio; Sp - Estrato superior; e PA Povoamento adulto. Fonte: Autores.

A posição sociológica indica a distribuição das espécies nos diferentes estratos, permitindo urna análise da composição florística no sentido vertical da floresta. A posição sociológica absoluta de uma espécie é obtida pela soma de seus valores fitossociológicos em cada estrato. A posição sociológica relativa expressa o valor da posição sociológica para cada espécie em percentagem dos valores absolutos (Finol, 1971).

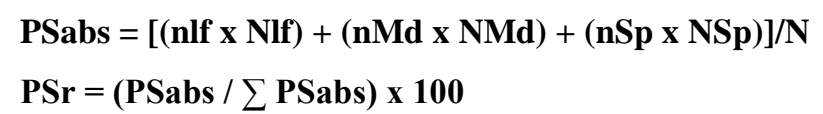

Onde:

$$
\begin{aligned}
\text { PSabs } & =\text { Posição sociológica absoluta; } \\
\text { PSr } & =\text { Posição sociológica relativa; }
\end{aligned}
$$

Nlf, NMd, NSp = Número total de indivíduos nos estratos;

Nlf, $\mathrm{nMd}, \mathrm{nSp}$ = Número de indivíduos de cada espécie em cada estrato;

$$
\begin{gathered}
\text { If }=\text { Estrato inferior; } \\
\mathrm{Md}=\text { Estrato médio; } \mathrm{e} \\
\mathrm{Sp}=\text { Estrato superior }
\end{gathered}
$$

O índice de valor de importância ampliado (Finol, 1971) é o valor resultante da avaliação do componente vertical da floresta e que incorpora os parâmetros posição sociológica e regeneração natural na análise estrutural. O índice permite uma caracterização mais qualitativa na avaliação ecológica das espécies em complemento ao IVI. Segundo Jardim \& Hosokawa (1986/87), o índice define com melhor clareza a importância ecológica das espécies no maciço florestal e é de grande utilidade na adoção de técnicas de manejo. 
Onde:

VIA = Valor de importância ampliado;

ABri = Abundancia relativa;

DMri = Dominância relativa;

FRri $=$ Frequência relativa;

$\mathrm{PSr}=$ Posição sociológica relativa; e

$\mathrm{PGr}=$ Regeneração natural relativa

\section{Resultados e Discussão}

A análise dos parâmetros estruturais considerou, entre outros, a importância ecológica das espécies determinada pelos descritores de Abundância, Frequência e Dominância como forma de escalonar sua importância ecológica nas comunidades avaliadas (Áreas 1, 2 e 3).

$\mathrm{Na}$ tabela 2, estão apresentados os valores de importância Ecológicas das Famílias (VIP $\geq 3 \%$ ) com maior riqueza florística na comunidade estudada. $\mathrm{Na}$ área $\mathrm{A} 2$, o posicionamento das famílias permanece inalterado até a $5^{\mathrm{a}}$ posição, quando ocorre uma alternância de Lecythidaceae por Mimosaceae (Tabela 4). A explicação é que a família Lecythidaceae contribuiu com duas espécies, contribuindo para que os valores de dominância e frequência relativas alcançadas pelas espécies Enterolubium maximum e Pithecelobium jupumba fossem maiores do que os alcançados pela espécie Alantoma Lineata, apesar de seu alto valor de abundância relativa, ver tabela 4.

Tabela 2. Valores de Abundância, Dominância, Frequência e Índice de Valor de Importância para Família (VIF $\geq 3 \%$ ) nas áreas contíguas (A1), adjacentes (A2) e de entorno (A3) no P.E.M.B.

\begin{tabular}{|c|c|c|c|c|c|c|c|}
\hline FAMÍLIAS & NI & Abr & DMr & FRr & VIF & VIFr & VIF.ac \\
\hline \multicolumn{8}{|l|}{ ÁREA A1 - CONTÍGUA } \\
\hline CLUSIACEAE & 441 & 31,82 & 35,45 & 15,66 & 82,92 & 27,64 & 27,64 \\
\hline ARECACEAE & 381 & 27,49 & 14,95 & 15,11 & 57,55 & 19,18 & 46,82 \\
\hline FABACEAE & 176 & 12,7 & 13,36 & 14,15 & 40,62 & 13,64 & 60,64 \\
\hline MYRISTICACEAE & 132 & 9,52 & 11,58 & 12,36 & 33,47 & 11,16 & 71,62 \\
\hline LECYTHIDACEAE & 105 & 7,58 & 6,12 & 10,16 & 23,86 & 7,95 & 79,57 \\
\hline MIMOSACEAE & 61 & 4,4 & 5,64 & 10,44 & 20,48 & 6,63 & 86,2 \\
\hline CAESALPINIACEAE & 17 & 1,23 & 4,28 & 4,4 & 9,9 & 3,3 & 89,5 \\
\hline \multicolumn{8}{|l|}{ ÁREA A2 - ADJACENTE } \\
\hline CLUSIACEAE & 613 & 35,03 & 35,35 & 14,76 & 85,14 & 28,38 & 28,38 \\
\hline ARECACEAE & 433 & 24,74 & 16,7 & 13,44 & 54,88 & 18,29 & 46,67 \\
\hline FABACEAE & 189 & 10,8 & 13,73 & 14,54 & 39,07 & 13,02 & 59,69 \\
\hline MIMOSACEAE & 143 & 8,17 & 9,67 & 11,89 & 29,73 & 9,91 & 69,6 \\
\hline MYRISTICACEAE & 108 & 6,17 & 9,35 & 11,45 & 26,97 & 8,99 & 78,39 \\
\hline LECYTHIDACEAE & 107 & 6,11 & 5,9 & 9,03 & 21,05 & 7,02 & 85,61 \\
\hline ANNONACEAE & 51 & 2,91 & 2,38 & 6,83 & 12,12 & 4,04 & 89,65 \\
\hline EBENACEAE & 39 & 2,23 & 1,26 & 5,73 & 9,22 & 3,07 & 92,72 \\
\hline
\end{tabular}




\begin{tabular}{cccccccc}
\hline ÁREA A3 - ENTORNO & & & & & & & \\
\hline ARECACEAE & 51 & 30 & 12,5 & 14,75 & 57,25 & 19,8 & 19,18 \\
\hline FABACEAE & 30 & 17,65 & 16,11 & 16,39 & 50,15 & 16,72 & 35,8 \\
\hline CLUSIACEAE & 31 & 18,24 & 13,31 & 13,11 & 44,66 & 14,89 & 50,69 \\
\hline MYRISTICACEAE & 19 & 11,17 & 10,86 & 11,48 & 35,51 & 11,17 & 61,86 \\
\hline CAESALPINIACEAE & 8 & 4,7 & 17,62 & 11,48 & 33,2 & 11,07 & 73,03 \\
\hline LECYTHIDACEAE & 14 & 8,23 & 5,99 & 9,84 & 24,06 & 8,02 & 81,05 \\
\hline MORACEAE & 2 & 1,17 & 16,61 & 3,28 & 21,06 & 7,02 & 88,07 \\
\hline MIMOSACEAE & 9 & 5,28 & 3,84 & 11,48 & 20,6 & 6,87 & 94,94
\end{tabular}

$\mathrm{NI}=\mathrm{N}^{\mathrm{a}}$ de indivíduos; $\mathrm{AB}=$ Abundância; $\mathrm{DM}=$ Dominância; $\mathrm{FR}=$ Frequência; VIF = Valor de Importância para a Família; $\mathrm{r}=\mathrm{Valor}$ Relativo; $a c=$ Valor Acumulado. Fonte: Autores.

Na área A3, observa-se também uma mudança na posição das famílias Arecaceae, que ficou na primeira posição e Clusiaceae que passou da primeira para a terceira posição. A família Caesalpiniaceae ganhou em importância de Lecythidaceae enquanto que a Família Moraceae, assumiu a pela primeira vez a $5^{a}$ posição e Mimosaceae caiu para $6^{\mathrm{a}}$ (Tabela 5). A ascensão da família Arecaceae foi influenciada pelo alto valor de abundância e frequências relativas da espécie Euterpe oleraceae que ocupou a primeira posição e Mauritia carana a $4^{\mathrm{a}}$ devido sua baixa dominância, apesar de que manteve os altos valores de abundância e frequência. Também merece ser citado o elevado valor de dominância relativa alcançada pela espécie Maximliliana regia que pertence à família das Arecaceas.

A ascensão da família Moraceae foi influenciada pela ocorrência da espécie Brosimum parinarioides. Para essa espécie, a presença de apenas um indivíduo foi determinante para o posicionamento da família devido ao seu alto valor de dominância relativa, sendo este o $2^{\circ}$ maior valor, só perdendo para Dimorphanda macrostachia que contribuiu com oito indivíduos (Tabela 5).

Tabela 3. Importância ecológica das espécies que apresentam valores de (IVI e IVIA $\geq 1 \%$ ) Valor de Importância Ecológico e Valor de Importância Ecológico Ampliado das espécies nas áreas contíguas (A1) no P.E.M.B.

\begin{tabular}{|c|c|c|c|c|c|c|c|c|c|c|c|c|c|}
\hline ESPÉCIES & NI & $\mathbf{A B r}$ & FRr & DMr & IVI & IVIr & PSr & PSr.ac & RGr & RGr.ac & IVIA & IVIA.r & IVIA.ac \\
\hline Mauritia carana & 326 & 25,8 & 11,4 & 12,8 & 49,9 & 16,7 & 34,2 & 34,24 & 6,54 & 6,54 & 90,7 & 18,1 & 18,14 \\
\hline $\begin{array}{c}\text { Caraipa } \\
\text { grandiflora }\end{array}$ & 199 & 14,7 & 10,7 & 14,6 & 40,1 & 13,4 & 13 & 47,23 & 11,5 & 18,08 & 64,6 & 12,9 & 31,06 \\
\hline $\begin{array}{c}\text { Virola } \\
\text { surinamensis }\end{array}$ & 132 & 9,83 & 10,1 & 11,7 & 31,5 & 10,5 & 8,14 & 55,37 & 7,46 & 25,54 & 47,1 & 9,43 & 40,49 \\
\hline $\begin{array}{l}\text { Symphonia } \\
\text { globulifera }\end{array}$ & 119 & 8,12 & 9,38 & 11,9 & 29,4 & 9,78 & 6,14 & 61,51 & 11,5 & 37,05 & 47 & 9,4 & 49,89 \\
\hline $\begin{array}{c}\text { Macrolobium } \\
\text { bifolium }\end{array}$ & 124 & 8,85 & 9,15 & 8,07 & 26,1 & 8,69 & 8,55 & 70,06 & 9,62 & 46,67 & 44,2 & 8,85 & 58,74 \\
\hline $\begin{array}{c}\text { Calophyllum } \\
\text { brasiliensis }\end{array}$ & 121 & 8,69 & 8,48 & 8,98 & 26,2 & 8,72 & 6,42 & 76,48 & 8,82 & 55,49 & 41,4 & 8,28 & 67,02 \\
\hline $\begin{array}{c}\text { Allantoma } \\
\text { lineata }\end{array}$ & 105 & 7,64 & 7,59 & 6,13 & 21,4 & 7,12 & 7,43 & 83,91 & 8,02 & 63,51 & 36,8 & 7,36 & 74,38 \\
\hline
\end{tabular}




\begin{tabular}{|c|c|c|c|c|c|c|c|c|c|c|c|c|c|}
\hline $\begin{array}{c}\text { Enterolobium } \\
\text { maximum }\end{array}$ & 57 & 3,49 & 6,47 & 5,08 & 15 & 5,01 & 3,37 & 87,28 & 8,78 & 72,29 & 27,2 & 5,43 & 79,81 \\
\hline Euterpe oleracea & 50 & 2,76 & 2,9 & 1,51 & 7,17 & 2,39 & 3,51 & 90,79 & 9,09 & 81,38 & 19,8 & 3,95 & 83,76 \\
\hline $\begin{array}{c}\text { Taralea } \\
\text { opositifolia }\end{array}$ & 43 & 2,84 & 5,8 & 2,94 & 11,6 & 3,86 & 3,02 & 93,81 & 4,23 & 85,62 & 18,8 & 3,76 & 87,52 \\
\hline $\begin{array}{l}\text { Diospirus } \\
\text { melinonni }\end{array}$ & 20 & 1,22 & 2,68 & 0,84 & 4,74 & 1,58 & 1,27 & 95,08 & 3,73 & 89,34 & 9,74 & 1,98 & 89,5 \\
\hline $\begin{array}{l}\text { Dimorphanda } \\
\text { macrostachia }\end{array}$ & 16 & 1,3 & 3,35 & 4,23 & 8,88 & 2,96 & 0,77 & 95,85 & 0 & 89,34 & 9,65 & 1,93 & 91,43 \\
\hline $\begin{array}{c}\text { Licania } \\
\text { heteromorfa }\end{array}$ & 105 & 0,32 & 0,89 & 0,16 & 1,37 & 0,46 & 0,44 & 96,29 & 4,66 & 94 & 6,47 & 1,29 & 92,72 \\
\hline Himantatus sp. & 11 & 0,81 & 1,79 & 0,9 & 2,99 & 1 & 0,95 & 97,24 & 0,76 & 94,76 & 4,7 & 0,94 & 93,66 \\
\hline Xylopia nitida & 8 & 0,41 & 1,12 & 0,47 & 2 & 0,67 & 0,32 & 97,56 & 2,02 & 96,78 & 4,34 & 0,86 & 94,52 \\
\hline $\begin{array}{l}\text { Ormosia } \\
\text { coutinihoi }\end{array}$ & 6 & 0,41 & 1,12 & 1,45 & 2,98 & 0,99 & 0,32 & 97,88 & 0,76 & 97,54 & 4,06 & 0,81 & 95,33 \\
\hline $\begin{array}{c}\text { Brosimum } \\
\text { parinaroides }\end{array}$ & 1 & 0,08 & 0,22 & 2,97 & 3,27 & 1,09 & 0,03 & 97,91 & 0 & 97,54 & 3,3 & 0,66 & 95,99 \\
\hline $\begin{array}{c}\text { Ficus } \\
\text { antihelminthia }\end{array}$ & 4 & 0,32 & 0,67 & 1,36 & 2,35 & 0,78 & 0,14 & 98,05 & 0 & 97,54 & 2,49 & 0,48 & 96,47 \\
\hline $\begin{array}{c}\text { Tapirira } \\
\text { guianensis }\end{array}$ & 6 & 0,49 & 1,12 & 0,51 & 2,12 & 0,71 & 0,35 & 98,04 & 0 & 97,54 & 2,47 & 0,49 & 96,96 \\
\hline $\begin{array}{c}\text { Clusia } \\
\text { grandiflora }\end{array}$ & 3 & 0,24 & 0,67 & 1,09 & 2 & 0,67 & 0,18 & 98,58 & 0 & 97,54 & 2,18 & 0,43 & 97,39 \\
\hline $\begin{array}{c}\text { Pithecelobiu } \\
\text { jupumba }\end{array}$ & 4 & 0,32 & 89 & 0,47 & 6,95 & 4,27 & 0,21 & 98,79 & 0 & 97,54 & 1,89 & 0,37 & 97,76 \\
\hline Dipterix odarata & 2 & 0,16 & 0,22 & 0,68 & 1,06 & 0,35 & 0,15 & 98,94 & 0 & 97,54 & 1,21 & 0,42 & 98,18 \\
\hline $\begin{array}{c}\text { Hevea } \\
\text { brasiliensis }\end{array}$ & 2 & 0,16 & 0,45 & 0,42 & 1,03 & 0,34 & 0,15 & 99,09 & 0 & 97,54 & 1,18 & 0,23 & 98,41 \\
\hline $\begin{array}{c}\text { Socratea } \\
\text { exorrhizia }\end{array}$ & 2 & 0 & 0 & 0 & 0 & 0 & 0 & 99,09 & 1,08 & 98,62 & 1,08 & 0,21 & 98,62 \\
\hline
\end{tabular}

$\mathrm{NI}=\mathrm{N}^{\mathrm{o}}$ de indivíduos; $\mathrm{ABr}=$ Abundância relativa; $\mathrm{FRr}=$ Frequência Relativa; $\mathrm{DMr}=$ Dominância Relativa; IVI = Valor de importância; $\mathrm{RGr}=$ Regeneração natural relativa; $\mathrm{ac}=$ valor acumulado; $\mathrm{PSr}=$ Posição sociocológica relativa; $\mathrm{r}=$ valor relativo em \%; IVIA = Valor de importância ampliado. Fonte: Autores.

Observa-se que nas áreas $\mathrm{Al}$ e A2, ocorreu um equilíbrio nos valores de VIFs para as Famílias mais importantes Clusiaceae, Arecaceae e Fabaceae. Destaca-se em importância na Área A3, as famílias Arecacea, Fabaceae, Clusiaceae e Caesalpiniaceae.

Observações idênticas foram feitas por Muniz (1994), na Reserva de Sacavém (MA), quanto a valores de IVIs e IVCs das famílias Arecaceae e Moraceae. A primeira assumiu a $5^{\mathrm{a}}$ posição em IVI e $6^{\mathrm{a}}$ em IVC. A alternância segundo o autor foi influênciada pelos altos valores de densidade e frequência relativas para Arecacea, enquanto que Moraceae apresenta alta e 
média dominância embora, suas frequências fossem quase desprezíveis.

Tabela 4. Importância ecológica para espécies que apresentam valores de (IVI e IVIA $\geq 1 \%$ ) Valor de Importância cológico e Valor de Importância ecológico ampliado das espécies nas áreas adjacentes (A2) no P.E.M.B.

\begin{tabular}{|c|c|c|c|c|c|c|c|c|c|c|c|c|c|}
\hline Espécies & NI & $\mathbf{A B r}$ & FRr & DMr & IVI & IVIr & PSr & PSr.ac & RGr & RGr.ac & IVIA & $\begin{array}{c}\text { IVIA } \\
\mathbf{r}\end{array}$ & IVIAr.ac \\
\hline $\begin{array}{c}\text { Caraipa } \\
\text { grandiflora }\end{array}$ & 357 & 20,7 & 11 & 18,5 & 50,1 & 16,7 & 18,8 & 18,8 & 17,1 & 17,13 & 86,4 & 17,3 & 17,2 \\
\hline Mauritia carana & 355 & 20,8 & 9,64 & 10,9 & 41,3 & 13,7 & 27,9 & 46,6 & 6,5 & 33,66 & 85,7 & 19,7 & 34,4 \\
\hline $\begin{array}{l}\text { Symphonia } \\
\text { globulifera }\end{array}$ & 181 & 10,7 & 10,5 & 12,9 & 34,1 & 11,4 & 8,9 & 55,6 & 6,65 & 40,31 & 49,7 & 9,93 & 44,3 \\
\hline $\begin{array}{c}\text { Virola } \\
\text { surinamensis }\end{array}$ & 143 & 8,32 & 9,12 & 9,77 & 27,2 & 9,07 & 6,3 & 61,9 & 7,12 & 47 & 40,7 & 8,13 & 52,4 \\
\hline $\begin{array}{c}\text { Macrolobiu } \\
\text { bifolium }\end{array}$ & 102 & 5,84 & 7,4 & 6,89 & 20,1 & 6,71 & 5,6 & 67,6 & 7,3 & 54,73 & 33,1 & 6,62 & 65,4 \\
\hline Alantoma lineata & 105 & 5,84 & 6,88 & 5,58 & 18,3 & 6,1 & 8,8 & 73,44 & 7,49 & 62,22 & 31,6 & 6,32 & 65,4 \\
\hline $\begin{array}{c}\text { Enterolium } \\
\text { maximum }\end{array}$ & 76 & 4,26 & 7,57 & 6,54 & 18,4 & 6,12 & 4,0 & 77,45 & 6,5 & 68,72 & 28,9 & 5,77 & 71,1 \\
\hline $\begin{array}{c}\text { Calophyllum } \\
\text { brasiliensis }\end{array}$ & 74 & 4,32 & 6,88 & 3,94 & 15,1 & 5,05 & 3,9 & 81,36 & 3,55 & 72,27 & 22,6 & 4,52 & 75,7 \\
\hline $\begin{array}{c}\text { Taralea } \\
\text { opositifolia }\end{array}$ & 71 & 4,32 & 6,71 & 4,8 & 15,8 & 5,28 & 4,2 & 85,64 & 1,92 & 74,19 & 22,3 & 4,4 & 80,1 \\
\hline $\begin{array}{c}\text { Euterpe } \\
\text { oleraceae }\end{array}$ & 65 & 2,67 & 1,2 & 1,48 & 5,35 & 1,78 & 3,5 & 89,14 & 9,01 & 83,2 & 17,9 & 3,57 & 83,6 \\
\hline Xylopia nitida & 51 & 3,05 & 4,82 & 2,39 & 10,3 & 3,42 & 2,86 & 92 & 2,08 & 85,28 & 15,2 & 3,04 & 86,7 \\
\hline $\begin{array}{l}\text { Diospirus } \\
\text { mellinonni }\end{array}$ & 39 & 2,22 & 3,96 & 1,24 & 7,42 & 2,47 & 2,65 & 94,65 & 2,36 & 87,64 & 12,4 & 2,48 & 89,2 \\
\hline $\begin{array}{c}\text { Pithecelobiu } \\
\text { jupumba }\end{array}$ & 31 & 1,91 & 3,44 & 2,74 & 8,09 & 2,7 & 1,43 & 96,08 & 0,53 & 88,17 & 10,1 & 2,01 & 91,2 \\
\hline Himantatus sp. & 17 & 0,7 & 1,55 & 0,41 & 2,66 & 0,89 & 0,83 & 96,91 & 4,04 & 92,21 & 7,53 & 1,5 & 92,7 \\
\hline $\begin{array}{c}\text { Licania } \\
\text { heteromorpha }\end{array}$ & 11 & 0,25 & 0,69 & 0,15 & 1,09 & 0,36 & 0,28 & 97,19 & 4,41 & 96,62 & 5,78 & 1,15 & 93,8 \\
\hline Mauritia armata & 7 & 0,44 & 0,34 & 3,44 & 4,22 & 1,41 & 0,18 & 97,37 & 0 & 96,62 & 4,4 & 0,88 & 94,7 \\
\hline $\begin{array}{c}\text { Ormosia } \\
\text { coutinihoi }\end{array}$ & 7 & 0,38 & 1,03 & 1,46 & 2,87 & 0,96 & 0,21 & 97,58 & 0,7 & 97,32 & 3,78 & 0,75 & 95,4 \\
\hline $\begin{array}{l}\text { Bombax } \\
\text { globosum }\end{array}$ & 6 & 0,13 & 0,17 & 1,67 & 1,97 & 0,66 & 0,05 & 97,63 & 1,44 & 98,76 & 3,46 & 0,69 & 96,1 \\
\hline $\begin{array}{l}\text { Dimorphanda } \\
\text { macrostachia }\end{array}$ & 7 & 0,44 & 1,03 & 0,57 & 2,04 & 0,68 & 0,36 & 97,99 & 0 & 98,76 & 2,4 & 0,48 & 96,6 \\
\hline Pterocarpus & 7 & 0,44 & 0,69 & 0,49 & 1,62 & 0,54 & 0,42 & 98,41 & 0 & 98,76 & 2,04 & 0,4 & 97,0 \\
\hline
\end{tabular}


amazonicus

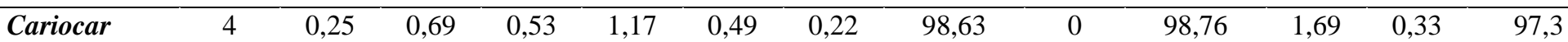

macrocarpum

Tapirira

$5 \quad 0,32 \quad 0,69$

0,32

1,33

0,44

0,19

98,82

0

98,76

1,52

0,3

97,6

guianensis

\section{Trichilia leicontei}

20

$0 \quad 0 \quad 0$

$0 \quad 98,82$

1,23

99,99

1,23

0,24

97,9

$\mathrm{NI}=\mathrm{N}^{\circ}$ de indivíduos; $\mathrm{ABr}=$ Abundância relativa; $\mathrm{FRr}=$ Frequência Relativa; $\mathrm{DMr}=$ Dominância Relativa. $\mathrm{IVI}=\mathrm{Valor}$ de importância; $\mathrm{RGr}=$ Regeneração natural relativa; $a c=$ valor acumulado. $\mathrm{PSr}=$ Posição sociocológica relativa; $\mathrm{r}=$ valor relativo em \%; IVIA $=$ Valor de importância ampliado. Fonte: Autores.

Dryflor (2016), confirma que vários tipos de vegetação possuem uma ou poucas espécies dominantes. Steege (2013) afirma que muitas espécies na floresta Amazônica coexistem sem que haja dominância verdadeira e que apenas um pequeno grupo responde por mais de $50 \%$ do número total de indivíduos.

Uma interpretação que pode ser dada aos valores em percentuais entre Colares e o Parque é que na sua maioria, ambas apresentaram equivalências a exemplo da substituição da família Cluusiaceae por Meliaceae e as alternâncias de Arecaceas por Meliaceae.

Tabela 5. Importância ecológica das espécies que apresentam valores de (IVI e IVIA $\geq 1 \%$ ) Valor de Importância Ecológico e Valor de Importância Ecológico Ampliado das espécies nas áreas A3 - do entorno na área do P.E.M.B.

\begin{tabular}{|c|c|c|c|c|c|c|c|c|c|c|c|c|c|}
\hline Espécies & NI & $\mathbf{A B r}$ & FRr & DMr & IVI & IVIr & PSr & PSr.ac & RGr & RGr.ac & IVIA & IVIAr & IVIAr.ac \\
\hline $\begin{array}{c}\text { Euterpe } \\
\text { oleraceae }\end{array}$ & 28 & 12,9 & 9,1 & 4,69 & 26,7 & 8,9 & 16,7 & 16,73 & 32,9 & 32,88 & 76,3 & 15,26 & 15,26 \\
\hline $\begin{array}{l}\text { Symphonia } \\
\text { globulifera }\end{array}$ & 24 & 13,6 & 9,1 & 10,2 & 32,9 & 11 & 12,7 & 29,42 & 17,2 & 50,04 & 62,8 & 12,54 & 27,8 \\
\hline $\begin{array}{c}\text { Virola } \\
\text { surinamensis }\end{array}$ & 19 & 11,6 & 9,1 & 10,9 & 31,5 & 10,5 & 9,33 & 38,75 & 10,7 & 60,75 & 51,6 & 10,31 & 38,11 \\
\hline $\begin{array}{c}\text { Mauritia } \\
\text { carana }\end{array}$ & 19 & 12,2 & 9,1 & 4,4 & 25,7 & 8,57 & 16,5 & 55,2 & 5,35 & 66,1 & 47,5 & 9,5 & 47,61 \\
\hline $\begin{array}{c}\text { Taralea } \\
\text { opositifolia }\end{array}$ & 13 & 7,48 & 7,8 & 4,19 & 19,5 & 6,48 & 6,7 & 61,9 & 10 & 76,13 & 36,2 & 7,23 & 54,84 \\
\hline $\begin{array}{l}\text { Dimorphanda } \\
\text { macrostachia }\end{array}$ & 8 & 5,44 & 9,1 & 17,4 & 31,9 & 10,6 & 3,57 & 65,47 & 0 & 76,13 & 35,5 & 7,09 & 61,63 \\
\hline $\begin{array}{c}\text { Alantoma } \\
\text { lineata }\end{array}$ & 14 & 9,52 & 7,8 & 6,1 & 23,4 & 7,8 & 9,6 & 75,07 & 0 & 76,13 & 33 & 6,6 & 68,53 \\
\hline $\begin{array}{c}\text { Macrolobium } \\
\text { bifolium }\end{array}$ & 11 & 6,8 & 5,2 & 3,92 & 15,9 & 5,3 & 5,77 & 80,84 & 5,53 & 81,48 & 27 & 5,4 & 73,93 \\
\hline $\begin{array}{c}\text { Ormosia } \\
\text { coutinihoi }\end{array}$ & 6 & 3,4 & 6,5 & 7,91 & 17,8 & 5,93 & 3,24 & 84,08 & 5,35 & 86,83 & 26,4 & 5,27 & 79,2 \\
\hline $\begin{array}{c}\text { Enterolobium } \\
\text { maximum }\end{array}$ & 7 & 4,08 & 5,2 & 1,87 & 11,1 & 3,71 & 4,41 & 88,49 & 5,52 & 92,35 & 21,1 & 4,21 & 83,41 \\
\hline
\end{tabular}




\begin{tabular}{|c|c|c|c|c|c|c|c|c|c|c|c|c|c|}
\hline $\begin{array}{c}\text { Brosimum } \\
\text { parinaroides }\end{array}$ & 1 & 0,68 & 1,3 & 16,2 & 18,2 & 6,05 & 0,47 & 88,96 & 0 & 92,35 & 18,6 & 3,72 & 87,13 \\
\hline $\begin{array}{c}\text { Caraipa } \\
\text { grandiflora }\end{array}$ & 5 & 3,4 & 5,2 & 1,75 & 10,3 & 3,47 & 4,13 & 93,09 & 0 & 92,35 & 14,5 & 2,89 & 90,02 \\
\hline $\begin{array}{c}\text { Socratea } \\
\text { exorrthiza }\end{array}$ & 2 & 0 & 0 & 0 & 0 & 0 & 0 & 93,09 & 7,65 & 100 & 7,65 & 1,53 & 91,55 \\
\hline $\begin{array}{c}\text { Pithecelobium } \\
\text { jupumba }\end{array}$ & 2 & 1,36 & 2,6 & 1,98 & 5,94 & 1,98 & 0,77 & 93,86 & 0 & 100 & 6,71 & 1,34 & 92,89 \\
\hline $\begin{array}{c}\text { Tapiriria } \\
\text { guianensis }\end{array}$ & 2 & 1,36 & 1,3 & 1,14 & 3,8 & 1,26 & 0,77 & 94,63 & 0 & 100 & 4,57 & 0,91 & 93,8 \\
\hline $\begin{array}{c}\text { maximiniana } \\
\text { regia }\end{array}$ & 1 & 0,68 & 1,3 & 2,08 & 4,06 & 1,35 & 0,47 & 95,1 & 0 & 100 & 4,53 & 0,9 & 94,7 \\
\hline $\begin{array}{c}\text { Hevea } \\
\text { brasiliensis }\end{array}$ & 1 & 06,8 & 1,3 & 2,08 & 4,06 & 1,35 & 0,47 & 95,57 & 0 & 100 & 4,53 & 0,9 & 95,6 \\
\hline $\begin{array}{l}\text { Cecropia } \\
\text { fisifolia }\end{array}$ & 1 & 0,68 & 1,3 & 0,76 & 2,74 & 0,91 & 0,47 & 96,04 & 0 & 100 & 3,21 & 0,64 & 96,24 \\
\hline $\begin{array}{c}\text { Calophyllum } \\
\text { brasiliensis }\end{array}$ & 1 & 0,68 & 1,3 & 0,7 & 2,68 & 0,89 & 0,47 & 96,51 & 0 & 100 & 3,15 & 0,63 & 96,87 \\
\hline $\begin{array}{c}\text { Cariocar } \\
\text { macrocarpum }\end{array}$ & 1 & 0,68 & 1,3 & 0,24 & 2,22 & 0,74 & 0,91 & 97,42 & 0 & 100 & 3,13 & 0,62 & 97,49 \\
\hline $\begin{array}{c}\text { Vochisia } \\
\text { guianensis }\end{array}$ & 1 & 0,68 & 1,3 & 0,22 & 2,2 & 0,73 & 0,91 & 98,33 & 0 & 100 & 3,11 & 0,62 & 98,11 \\
\hline $\begin{array}{l}\text { Trichilia } \\
\text { leicontei }\end{array}$ & 1 & 0,68 & 1,3 & 0,19 & 2,17 & 0,72 & 0,9 & 99,24 & 0 & 100 & 3,08 & 0,61 & 98,72 \\
\hline $\begin{array}{c}\text { Chaumochiton } \\
\text { lecontei }\end{array}$ & 1 & 0,68 & 1,3 & 0,59 & 2,57 & 0,86 & 0,47 & 99,71 & 0 & 100 & 3,04 & 0,6 & 99,32 \\
\hline $\begin{array}{c}\text { Oneocapus } \\
\text { distichus }\end{array}$ & 1 & 0,68 & 1,3 & 0,58 & 2,56 & 0,85 & 0,3 & 100 & 0 & 100 & 2,86 & 0,57 & 99,89 \\
\hline
\end{tabular}

$\mathrm{NI}=\mathrm{N}^{\mathrm{o}}$ de indivíduos; $\mathrm{ABr}=$ Abundância relativa; $\mathrm{FRr}=$ Frequência Relativa; $\mathrm{DMr}=$ Dominância Relativa. IVI $=\mathrm{Valor}$ de importância; $\mathrm{RGr}=$ Regeneração natural relativa; $\mathrm{ac}=$ valor acumulado. $\mathrm{PSr}=$ Posição sociocológica relativa; $\mathrm{r}=$ valor relativo em \%; IVIA $=$ Valor de importância ampliado. Fonte: Autores.

A alta dominância da espécie Euterpe oleraceae (Açai) na área do estudo pode ter sido motivada por necessidades alimentares e ou comerciais consistido na indução natural por perfilhação. Já outras espécies da mesma família como Attaleae excelsa (Urucuri), que têm seu uso voltado a confecção de habitação, pode ter sofrido um efeito inverso, ou seja, sua população pode ter sido reduzida por uso predatório uma vez não ser prática comum sua domesticação. Igual motivo acontecido para a preservação da espécie Carapa guianensis (Andiroba), que tem sua grande aplicação com uso medicinal caseiro ou industrial para cosméticos. Sendo essa uma motivação mais que justificável para que a espécie fosse poupada da utilização com fins madeireiros. Por outro lado, as espécies das famílias Clusiaceae e Myristicaceae representadas pelas espécies Virola surinamensis (Virola) e Symphonia globulifera (Anani) possam ter sido comercializadas para a industria de laminação dado aos atrativos de preços e facilidades de acesso o que contribuiu para que estas apresentem baixos valores de abundância 
relativa na área.

Por outro lado, famílias com Clusiaceae e Myristicaceae e as espécies Caratpa grandiflora (Tamaquare), Calophilum brasiliensis (Jacareuba), Shymphonia globulifera (Anani) e Euterpe oleraceae (Açai) tiveram suas populações favorecidas após a implantação do Centro de Treinamento da Marinha Brasileira (área adjacente) há cinco décadas, por questões ligadas a uma maior vigilância da área o que possibilitou uma franca recuperação dessas populações.

As famílias mais representativas nas áreas estudadas posicionadas em ordem decrescente dos VIFs $\geq 3 \%$ (Valor de Importância para Famílias) estão representadas na Tabela 2. Para a área Al (Contíguas), a família com maior valor de VIF é Clusiaceae $(27,64 \%)$ graças aos valores de densidade, dominância e freqüência relativas das espécies Caraipa grandiflora, Symphonia glubulifera e Calophilum brasiliensis (tabela 3).

Figura 2. Famílias mais importantes por ordem de (VIF $\geq 2 \%)$ nas áreas $\mathrm{A} 1$ - contíguas, $\mathrm{A} 2$ - adjacentes e A3 - do entorno. Clus (Clusiaceae); Are (Arecaceae); Fab (Fabaceae); Myri (Myristicaceae); Lecy (Lecythidaceae); Mimo (Mimosaceae) Caes (Caesalpiniaceae); Mora (Moraceae); Anno (Annonaceae); Eben (Ebenaceae); Out (Outras) na área do P.E.M.B.

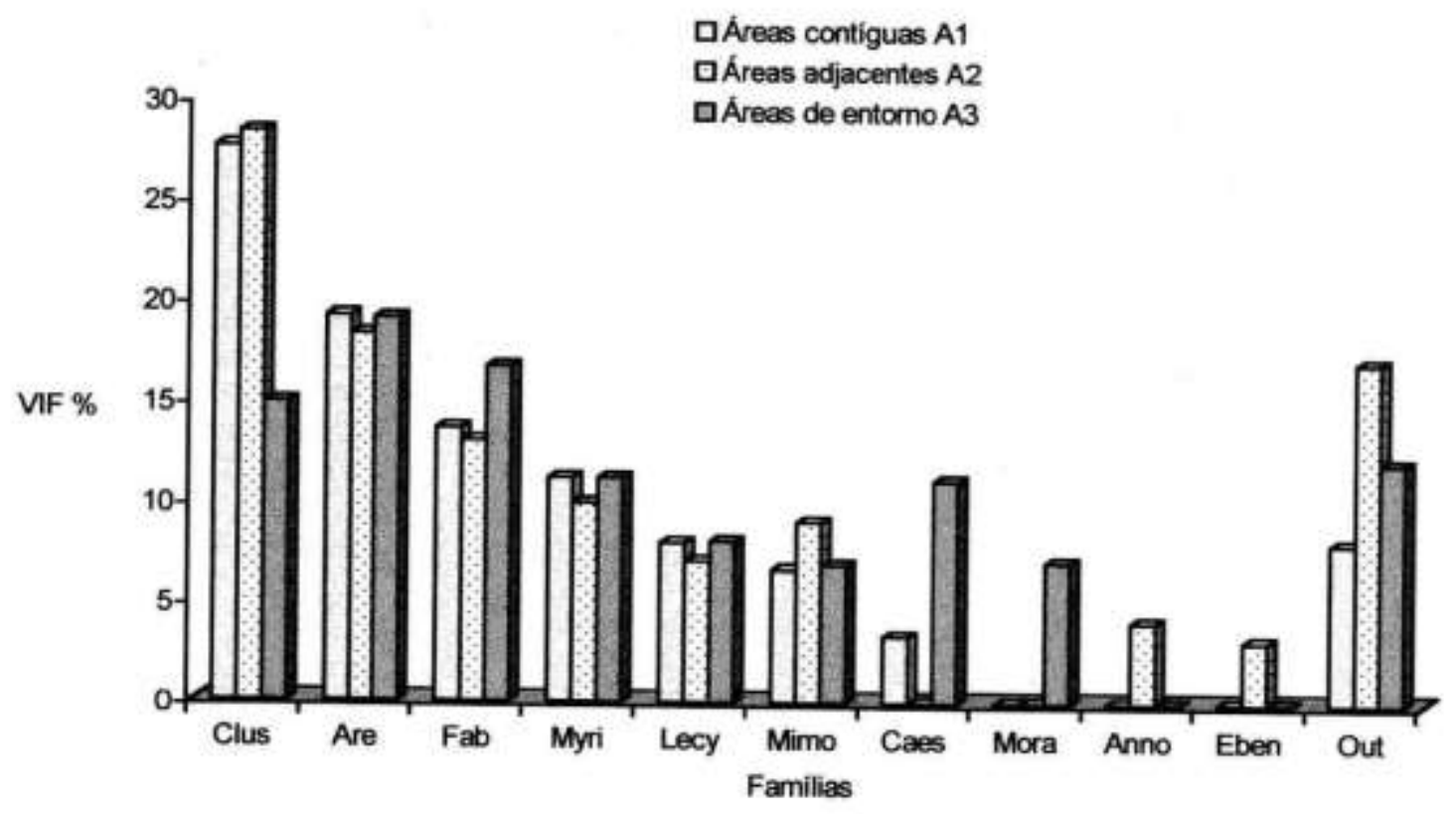

Fonte: Autores.

As famílias Arecaceae, Fabaceae, Mirysticaceae e Lecythidaceae ocupam as 2a, 3a, 4a e 5a posições em valores de VIFs. A Família Arecaceae apesar de ter como sua principal representante a espécie Mauritia carana, a qual possui a maior abundância relativa, perde em dominância para Caraipa grandiflora, fato que contribui com seu rebaixamento para a $2^{\mathrm{a}}$ posição (Figura 2 e Tabela 2).

Almeida et al (2004) constatou que a redução da diversidade de algumas espécies encontradas na várzea pode diminuir com a intervenção humana, pois como o grau de resiliência do ambiente é baixo devido a fatores como a inundação periódica, a salinidade e a velocidade de inundação de águas, a remoção de cobertura vegetal pode levar a perda do habitat, reconhecendo a importância ecológica e estrutural que as plantas desempenham neste ecossistema.

Na Figura 3, estão demonstradas as Famílias que apresentaram maior riqueza de espécies na área do Parque. Observase um equilíbrio entre as famílias Arecacea, Fabacea e Clusiaceae nas áreas A1, A2 e A3. Observa-se ainda, uma 
predominância de espécies das famílias Lecythidaceae, Bombacaceae, Cariocaraceae, Meliaceae e Burseraceae na área A2 (adjacentes).

Figura 3. Famílias com maior abundância de espécies nas áreas A1 - contíguas, A2 - Adjacentes e A3 - do entorno. Are (Arecaceae); Fab (Fabaceae); Clu (Clusiaceae); Mim (Mimosaceae); Mor (Moraceae); Lecy (Lecythidaceae); Bom (Bombaceae); Car (Cariocaraceae); Mel (Meliaceae); Bur (Burseraceae); Out (Outras) na área do P.E.M.B.

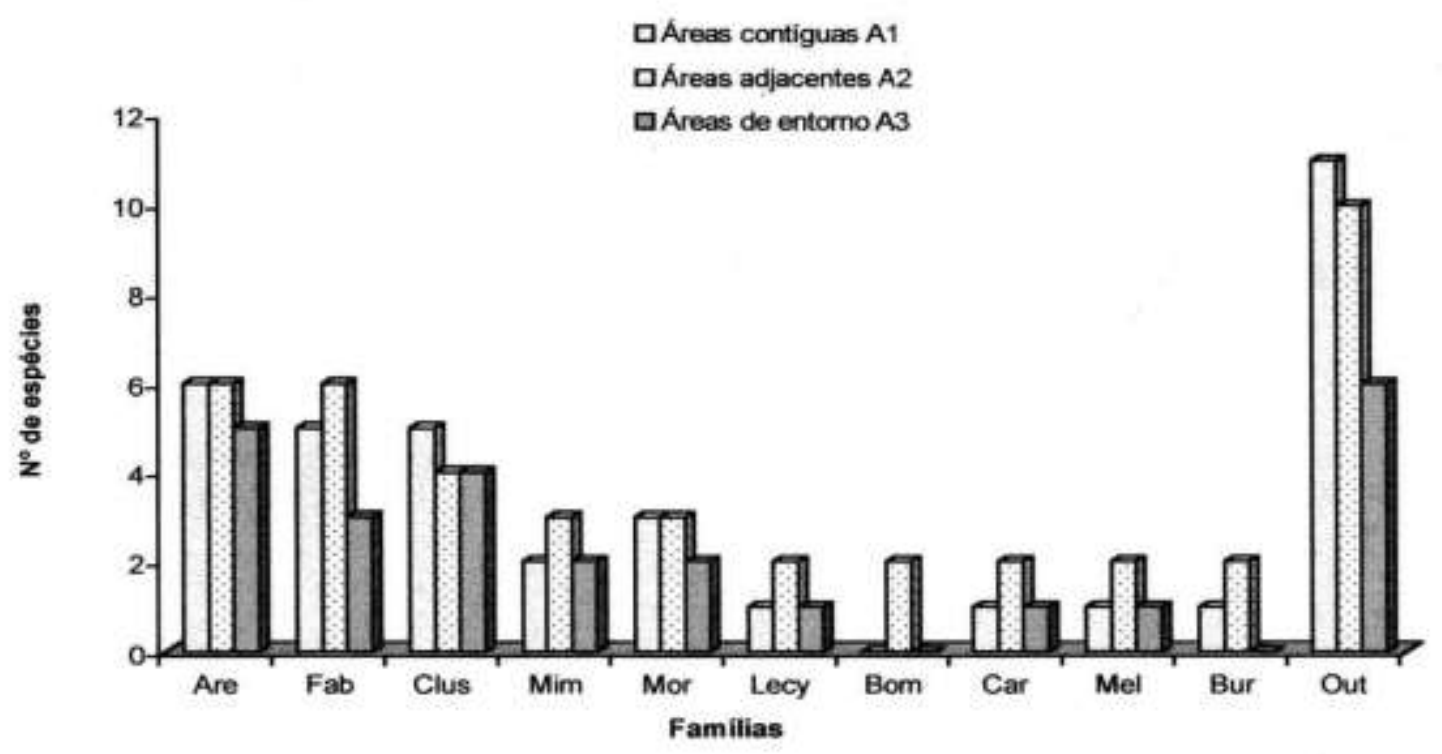

Fonte: Autores.

Na Figura 4, está demonstrada a relação entre a abundância e espécies nas áreas Al, A2 e A3 no Parque. Observa-se que nas três áreas avaliadas ocorreu um equilíbrio nos valores de abundância em que poucos indivíduos (40 ou 60\%), representam muitas espécies enquanto que poucas espécies representam alta abundância. 
Figura 4. Distribuição do número de indivíduos das espécies por categoria de abundância em intervalos de classe de (40 indivíduos) nas áreas A1 - contíguas, A2 - adjacentes e A3 - do entorno, que ocorreram na área do P.E.M.B.

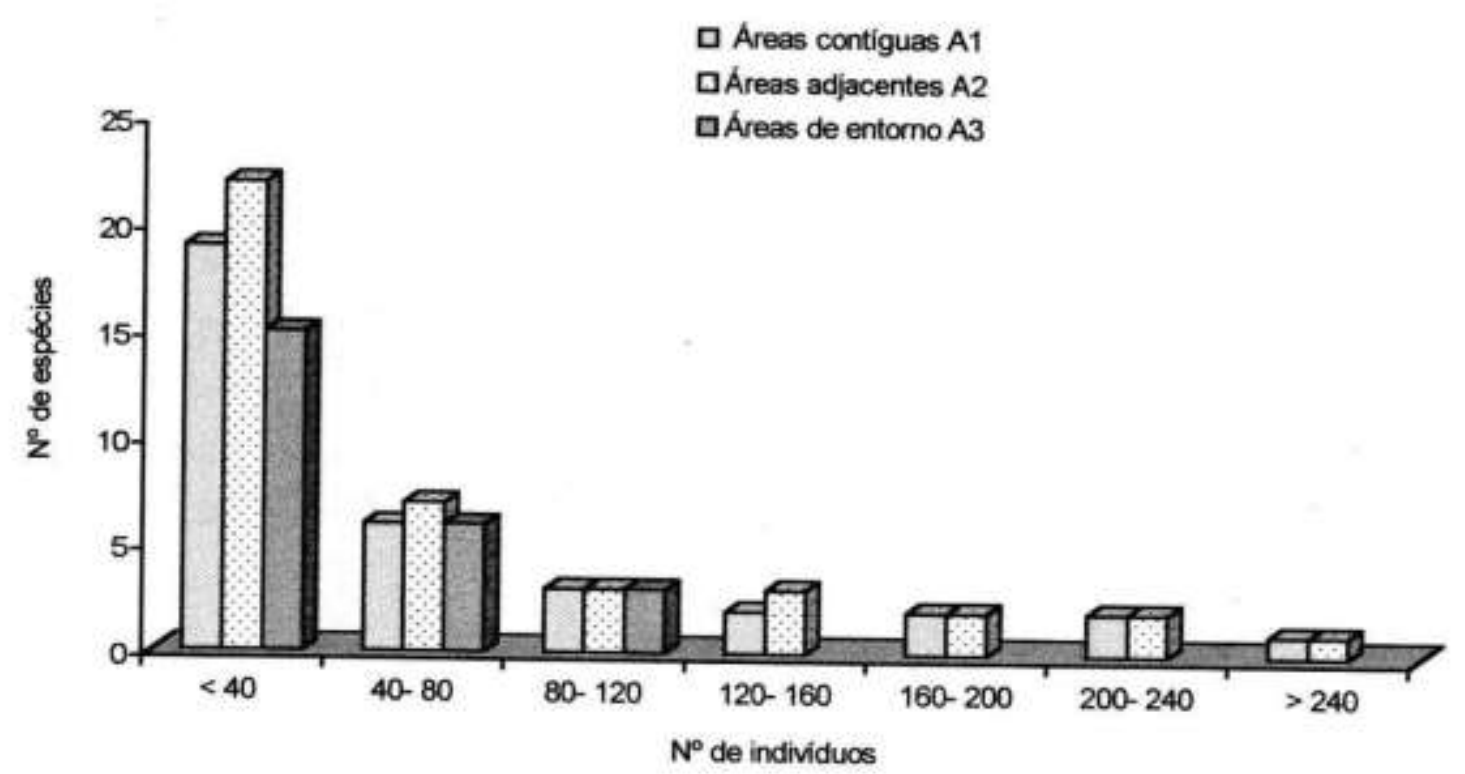

Fonte: Autores.

Condit et al (1996) afirmam que, via de regra, há grande quantidade de espécies raras que ocorrem em determinados locais podem não ocorrer em outras, sendo isso uma característica das próprias florestas tropicais, fazendo com que a curva de acumulação de espécies aumente indefinidamente com o aumento de uma área. Carim (2017) encontrou um alto valor de IVI representado por poucas espécies enquanto que muitas foram representadas por um número pequeno de indivíduos, tanto em área de igapó, como em área de várzea. No caso deste estudo, esses parâmetros estão melhor interpretados nas tabelas 10,11 e 12 e Figura 5.

Na Figura 5, estão demonstrados os valores de Importância ecológico das espécies que apresentam valores de IVIr > 3,5\% nas áreas A1, A2 e A3 no Parque. Observa-se que as espécies Caraipa grandiflora e Mauritia carana apresentaram maiores valores de IVIr\% nas três áreas avaliadas. 
Figura 5. Importância Ecológica para as espécies que apresentam valores de (IVIr $\geq 3,5 \%$ ) Valor de Importância Ecológico Relativo de espécies nas áreas A1 - contíguas, A2 - adjacentes e A3 - do entorno na área do P. E. M. B.

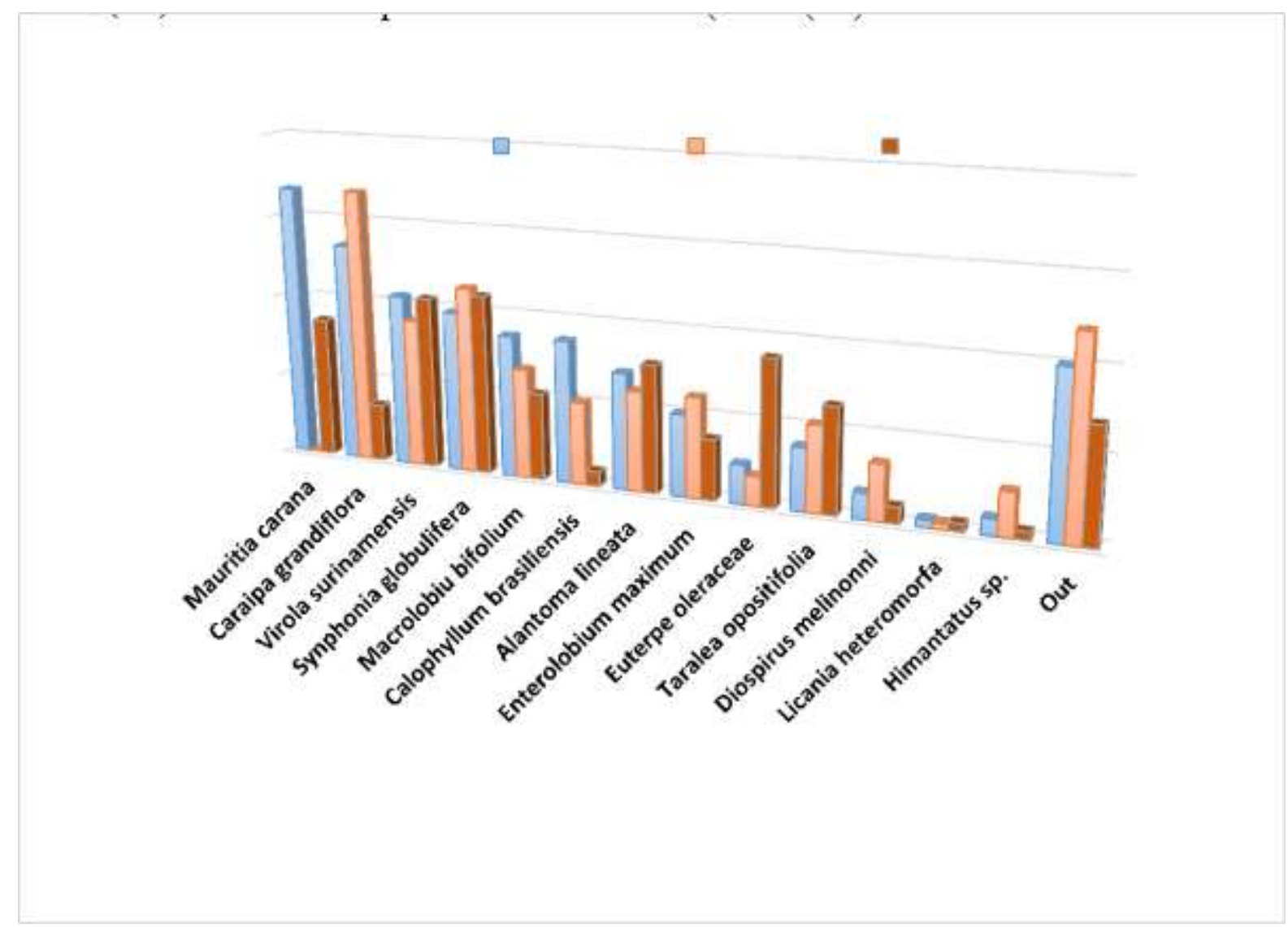

Fonte: Autores.

Observa-se uma equiparação nos valores de IVIr\% entre as espécies Caraipa grandiflora, Mauritia carana, Symphonia globulifera e Macrolobium bifolium nas áreas A1, A2 e A3. Observa-se ainda que as espécies Caraipa grandiflora e Enterolobium maximum não alcançaram um patamar de importância acima de 4\% de IVIr por isso não aparecem na Figura 5, compondo a área A3 (Marinha). Em contrapartida espécies como Euterpe oleraceae, Alantoma lineata e Taralea opositifolia foram as espécies mais importantes na referida área.

Mori (2019) afirma que o a composição funcional e a diversidade funcional de uma comunidade indicam os padrões gerais das espécies semelhantes em relação às características comuns no relacionamento entre si e nas condições do meio ambiente (relacionamento com patógenos e fatores abióticos, por exemplo). Essa organização determina que cada espécie ocupe seu espaço, onde desenvolvem suas funções, sendo isso um dos fatores determinantes na existência de formações vegetais com composição florística e características fisionômicas diferentes, contribuindo por dificultar sua delimitação e identificação dessas comunidades.

Comparou-se os valores de importância ecológica das espécies (IVI) e importância ecológica ampliada (IVIA) Figuras 5 e 6 e Tabelas 3 , 4 e 5 ).

Determinadas espécies ganharam ou perderam importância na comunidade florística em função da inclusão nas análises dos parâmetros da estrutura vertical (Regeneração natural e Posição sociológica).

As espécies que tiveram sua importância reduzida foram Calophylum brasiliensis, Dimorphanda macrostachia, Ormosia coutinhoi e Brosimum parinaroides. As espécies que tiveram sua importância ampliada foram Mauritia carana, Macrolobium bifolium, Alantoma lineata, Enterolobium maximum, Euterpe oleraceae e Taralea opositifolia. Algumas espécies 
pouco alteraram sua importância devido a regularidade na distribuição de representantes nas classes de estratificação dos IVIr\% e IVIAr\% como Caraipa grandiflora, Virola surinamensis e Symphonia globulifera sendo aqui consideradas como edificadoras do povoamento analisado (Tabelas 3,4 e 5 Figuras 5 e 6 ).

Observou-se que as espécies que ganharam importância foram as que obtiveram os maiores valores de posição sociológica e regeneração natural e as que perderam, apesar de possuir representantes nos estratos intermediário e superior, não apresentaram regeneração natural.

Na Figura 6, estão demonstrados os valores de Importância ecológica das espécies que apresentam valores de IVIA $\geq$ 3,5\% nas áreas Al, A2 e A3 no Parque. Observa-se que as espécies Mauritia carana, Caraipa grandiflora e Virola surinamensis apresentaram maiores valores de IVIAr \% nas três áreas avaliadas.

Figura 6. Importância ecológica das espécies que apresentam valores de (IVIAr $\geq 3,5 \%$ ) Valor de Importância Ecológico Ampliado relativo nas áreas A1 - contíguas, A2 - adjacentes e A3 - do entorno na área do P. E. M. B.

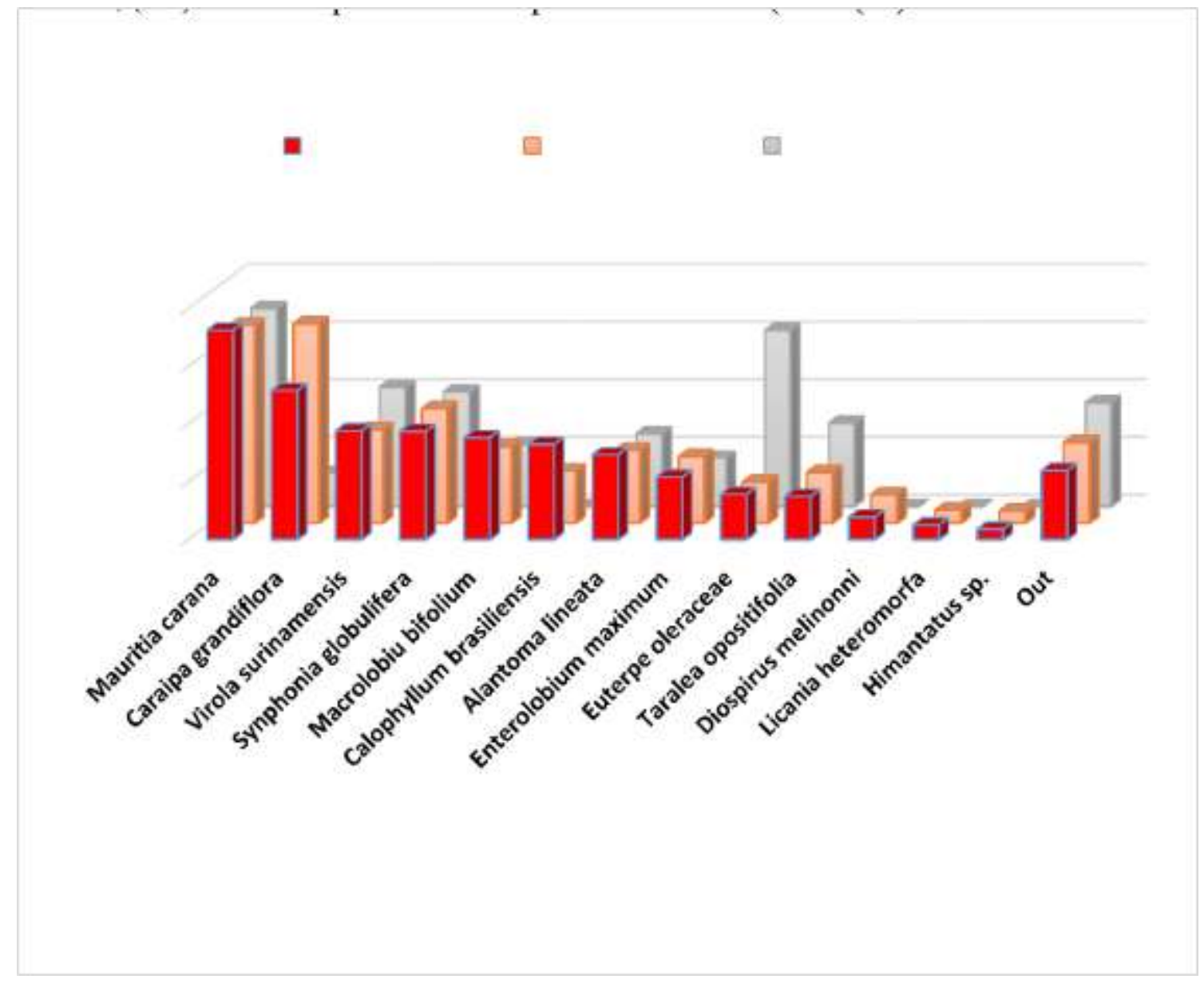

Fonte: Autores.

No estudo na área do Parque, 54\% das espécies levantadas ganharam importância quando da inclusão dos parâmetros regeneração natural e posição sociológica, sendo que pelo menos duas dessas espécies pertencem a família Arecaceae, Mauritia carana e Euterpe oleraceae.

No caso de várzeas estuarinas o elemento mais característico da florística são palmeiras (JARDIM, 2007). Devido a essa característica e, em especial, àquelas espécies que apresentam estratégias de sobrevivência por perfilhações, a exemplo do açaí (Euterpe oleraceae), caranã (Mauritia carana) e marajá (Bactris maraja) e que, por apresentarem essas peculiaridades, 
venham a ser uma excessão aos conceitos tradicionais de grupos ecológicos utilizados por (FINOL, 1971; PIRES, 1982). O primeiro afirma ser a ausência de regeneração uma característica que confere um caráter secundário as espécies que não apresentam representantes nessa categoria. O segundo autor identifica as espécies tolerantes como sendo aquelas que possuem elevada abundância de indivíduos na fase jovem.

Para a área A2, as espécies Caraipa grandiflora, Mauritia carana, Symphonia globulifera Virola surinamensis, Macrolobium bifolium, Alantoma lineata, Enterolobium maximum e Calophylum brasiliensis foram as que apresentaram maiores valores de IVI e IVIA (Tabela 11 e Figura 6).

$\mathrm{Na}$ área A3, as espécies foram Euterpe oleraceae, Symphonia globulifera, Virola surinamensis, Mauritia carana, Taralea opositifolia, Dimorphanda macrostachia, Alantoma lineata e Macrolobium bifolium (Tabela 5 Figura 6).

Avaliando-se parâmetros da estrutura vertical quanto a importância ecológica das espécies observa-se uma forte identidade nos valores de densidade e frequência relativos e posição sociológica, o mesmo não acontecendo com o parâmetro regeneração natural relativa.

$\mathrm{Na}$ área $\mathrm{Al}$, as espécies Caraipa grandiflora e Virola surinamensis ocupam as $2^{\mathrm{a}}$ e $3^{\mathrm{a}}$ posições em ordem decrescente de VIAr\%. A primeira apresenta maior valor de abundância relativa (14,70\%) e menor valor de frequência relativa (10,72\%), a segunda representa maior valor de frequência relativa $(10,05 \%)$ e menor valor de abundância relativa $(9,83 \%)$, porém, ambas apresentam altos valores de dominância relativa $(14,64 \%$ e $11,66 \%)$ respectivamente, valores estes que garantiram o posicionamento dessas espécies nos $2^{\mathrm{a}}$ e $3^{\mathrm{a}}$ lugares. No que concerne a valores de posição sociológica relativa, apenas a espécie Caraipa grandiflora manteve o $2^{\circ}$ lugar $(12,99 \%)$ enquanto que Virola surinamensis $(8,14 \%)$ cai do $3^{\circ}$ para o $4^{\circ}$ lugar e assumindo aquela posição a espécie Macrolobium bifolium (8,55\%).

Também as espécies Alantoma lineata que é a $7^{\mathrm{a}}$ e Calophylum brasiliensis a $6^{\mathrm{a}}$, possuem valores mais elevados para posição sociológica e considerando apenas esse item, ocupariam o $4^{\circ}$ e $5^{\circ}$ lugares. Comparando-se os valores da posição sociológica (PSr) e regeneração natural relativa (RGr), observa-se uma alternância significativa desses valores uma vez que algumas espécies estão bem representadas em ambos os parâmetros e outras simplesmente estão ausentes.

Espécies como Mauritia carana e Caraipa grandiflora possuem elevados valores de $\mathrm{PSr}$ (34,24\% e 12,99\%) contra (6,54\% e 11,54\%) para RGr, respectivamente. Algumas espécies como Symphonia globulifera, Macrolobium bifolium e Calophyllum brasiliensis apresentam baixos valores de $\operatorname{PSr}(6,14 \%, 8,55 \%$ e 6,42\%) e altos valores de $\mathrm{RGr}(11,55 \%, 9,62 \%$ e 8,82\%). Outras espécies apresentam um equilíbrio entre os valores de PSr e RGr a exemplo de Taralea opositifolia (3,02\% e $4,33 \%)$ e Ormosia coutinhoi $(0,32 \%$ e $0,76 \%)$. Observa-se ainda que outras se alternam ora apresentando apenas valores num ou noutro parâmetro a exemplo de Brosimum parinarioides, Ficus anthihelmintia, Dipterix odorata e (Tabela 3).

Seguindo o mesmo raciocínio anterior, encontram-se na área A2 as espécies Caraipa grandiflora e Mauritia carana com $\operatorname{PSr}(18,81 \%$ e $27,88 \%)$ e RGr (17,13\% e 16,53\%) respectivamente. Ambas apresentam valores altos de RGr como Virola surinamensis, Macrolubium bifolium e Alantoma lineata $(7,12 \%, 7,30 \%$ 7,49\%) e $\mathrm{PSr}(6,32 \%, 5,69 \%$ e 5,81\%) respectivamente. Igualmente algumas espécies, apresentam valores bem equilibrados como Calophyllum brasiliensis, Guatteria ovalifolia, Diospirus melinonni. Outras espécies apresentam valores apenas em um ou outro parâmetro a exemplo de Mauritia armata, Dimorphanda macrostachia e Pterocarpus amazonicus (Tabela 4).

Por outro lado, espécies consideradas intermediárias nas áreas Al e A2 como Euterpe oleraceae, Taralea opositifolia e Dimorphanda macrostachia, que mantiveram sempre um valor alto de regeneração, exceto esta última que não apresentou regeneração, mantiveram sempre valores que indicam uma boa posição sociológica da espécie, passando a assumir na área A3, os $1^{\circ}, 5^{\circ}$ e $6^{\circ}$ lugares na ordem de IVIAr\%. Daí deduzir-se que essas espécies ao encontrarem condições propícias, como por exemplo, luminosidade, solos, clima ganharão importância e se estabelecerão na comunidade. Isso confirma a predisposição para uso no manejo da área, pela importância que representam na comunidade. (Tabelas 3, 4 e 5). 
Tonini (2019), confirma ser a ausência da regeneração um indicativo de que as espécies tenham um caráter secundário na comunidade. Uma nova abertura (clareira) pode garantir sua regeneração e assim estabelecer um ciclo, do contrário a espécie pode ser substituída.

\section{Conclusão}

As espécies Calophylum brasiliensis, Dimorphanda macrostachia, Ormosia coutinhoi e Brosimum parinaroides tiveram sua importância reduzida.

As espécies que tiveram sua importância ampliada foram Mauritia carana, Macrolobium bifolium, Alantoma lineata, Enterolobium maximum, Euterpe oleraceae e Taralea opositifolia.

Algumas espécies pouco alteraram sua importância devido a regularidade na distribuição de representantes nas classes de estratificação dos IVIr\% e IVIAr\% como Caraipa grandiflora, Virola surinamensis e Symphonia globulifera sendo aqui consideradas como edificadoras do povoamento analisado.

Observou-se que as espécies que ganharam importância foram as que obtiveram os maiores valores de posição sociológica e regeneração natural e as que perderam, apesar de possuir representantes nos estratos intermediário e superior, não apresentaram regeneração natural.

Os valores de Importância ecológica das espécies que apresentam valores de IVIA $\geq 3,5 \%$ nas áreas Al, A2 e A3. As espécies Mauritia carana, Caraipa grandiflora e Virola surinamensis apresentaram maiores valores de IVIAr \% nas três áreas avaliadas.

O presente artigo possibilita o entendimento acerca da composição florística de vegetação, sendo um tema fundamental para futuros trabalhos acadêmicos no contexto em foco.

\section{Referências}

Albuquerque, N. R. \& Molinari, D. C. (2020). Caracterização da Cobertura Vegetal no Alto Curso da Bacia do Igarapé do Mindu-Manaus (AM). Revista Brasileira de Geografia Física, 13 (01), 406-422.

Almeida S. S. \& Amaral D. D., Silva A. S. L. (2004). Análise florística e estrutura de florestas de Várzea no estuário amazônico. Acta Amazonica, 34 (4): 513 524.

Alencar, L. D. \& Cardoso, J. C. (2015). Paisagismo funcional: o uso de projetos que integram mais que ornamentação. Revista Ciência, Tecnologia \& Ambiente, 01 (01), $1-7$.

Barbosa, P. H. D., Costa, A. C. L., Cunha, A. C. \& Silva Junior, J. A. (2015). Variabilidade de elementos meteorológicos e de conforto térmico em diferentes ambientes na Amazônia brasileira. Revista Brasileira de Climatologia, 17, 98-118.

Campos, R. B. F. \& Castro, J. M. (2017). Áreas Verdes: Espaçõs Urbanos Negligenciados Impactando a Saúde. Saúde \& Transformação Social, 08 (01), 106 116.

Carim M. J. V., Wittman, F. K., Piedade M. T. F., Guimarães J.R. S. \& Tostes L. C. L. (2017). Composition, diversity, and structure of tidal "Várzea" and "Igapá" floodplain forest in eastern Amazonia, Brazil. Brazilian Journal of Botany. 40 (1), 115-124.

Carvalho, J. O. P. (1982) de. Análise estrutural da regeneração natural em floresta tropical densa na Região do Tapajós no Estado do Pará. Curitiba. Tese de Mestrado. UFPR.

Jardim M. A. G., Santos G. C., Medeiros T. D. S. \& Francez D. C. (2007). Diversidade e estrutura de palmeiras em floresta de várzea do estuário amazônico. Amazônia: Ciência \& Desenvolvimento, 2 (4), 67-84.

Conama, Resolução N. 357, de 17 de março de 2005 Publicada no DOU nº 053. de 18/03/2005, 58-63.

Condit, R. et al. (1996). Species-area and species individual relationships for tropical trees: a comparison of three 50-ha plots. Journal of Ecology, London, 84, $549-562$.

Cronquist, H. (1981). Na integrated system of classification of flowering plants. New York: Columbia University Press.

Degrande, E. J. S., Firmino, G. V. \& Torres, M. A. N. (2020). Dinâmica fluvial e caracterização limnológica do córrego do cedro, Presidente Prudente - São Paulo/Brasil. Revista Brasileira de Geografia Física, 13 (04), 1851-1869. 
Research, Society and Development, v. 10, n. 7, e38210716673, 2021

(CC BY 4.0) | ISSN 2525-3409 | DOI: http://dx.doi.org/10.33448/rsd-v10i7.16673

Dias, N., Francelino, D. \& Almeida, L. (2020). Análise da cobertura vegetal como indicador de qualidade de vida no município de barbacena-mg. enciclopédia biosfera, 17 (32).

Dias, S. F. et.al. (1991). Zoneamento Ecológico - Econômico do Estado do Pará. Belém. IDESP.

Dryflor. (2016). "Plant diversity patterns in neotropical dry forests and their conservation implications". Science, 353, 6306, 1383-1387.

EMBRAPA. (2018). Empresa Brasileira de Pesquisa Agropecuária. Centro Nacional de Pesquisa de Solos: Sistema brasileiro de classificação de solos. Brasília.

Finol, V.H. (1971). Nuevos parametros a considerarse en el análises estruturais de las Selvas Virgens Tropicales. Rev. For. Venezolana, Mérida, 14 (21), 29 42 .

IBGE. Instituto Brasileiro de Geografia e Estatística. Conjunto de mapas, arquivos vetoriais e documentos que identificam e classificam a vegetação brasileira, atual e pretérita, baseado em um sistema fisionômico-ambiental adaptado à classificação universal proposta pela UNESCO (2017).

Lamprecht, H. (1964). Ensayo sobre la estrutura floristica de la parte sur-oriental del bosque universitário " El Caimital" Estado Barinas. Rev. For.Venezolana, Mérida, 7, 10\11, 77 - 119 .

Matteucci, SD. \& Colma, A. (1982). Metodologia para el estudo de la vegetation. Washington, the General Secretariat of the Organization of Américan States, $168 \mathrm{p}$.

Mendes, F. S., Jardim, F. C., Carvalho, J. O. P., Souza, D. V., Araújo, C. B., Oliveira, M. G. \& Leal, E. S. (2013). Dinâmica da estrutura da vegetação do subbosque sob influência da exploração em uma floresta de terra firme no município de Moju - PA. Ciência Florestal, Santa Maria, 23 (2), 377-389, abr.-jun.

Mori, G. B. (2019). Estrutura funcional das comunidades arbóreas de florestas alagáveis na Amazônia Central. Manaus:[s.1], 2019.116 f.Tese (Doutorado Programa de Pós Graduação em Ecologia) --Coordenação do Programa de Pós-Graduação, INPA.

Moura, M. R. F., Martins, N. N. J. L. N. \& Almeida, Y. Y. G. (2020). A macrodrenagem urbana sob a ótica do tripé da sustentabilidade: uma análise dos canais do Recife-PE. Periódico Eletrônico Fórum Ambiental da Alta Paulista, 16, (2).

Muniz, F. H., Cesar, O. \& Monteiro, R. (1994). Aspectos florísticos quantitativos e comparativos da vegetação arbórea da Reserva Florestal do Sacavém, São Luís, Maranhão (Brasil). Acta Amazonica, 24 (3-4), 189-217.

Oliveira, A. A. (1997). Diversidade, estrutura e dinâmica do componente arbóreo de uma floresta de terra firme de Manaus, Amazonas. tese de Doutorado em Botânica. Instituto de Biociências da Universidade de São Paulo, São Paulo. 155p.

Sene, T. S., Santos, C. S., Scheffer, S. M., Moura, R. R. \& Costa, L. C. (2020). Política urbana da cidade de Ponta Grossa/PR: a ordenação do solo urbano e a sua relação com os recursos hídricos. Serviço Social em Revista, 23 (1), 160-177.

Steege, $\mathrm{H}$ ter, et al. (2013). Hyperdominance in the Amazonian tree flora. Science 342, 1243092.

Tonini, H. \& Baldoni, A. B. (2019). Estrutura e regeneração de Bertholletia excelsa Bonpl. em castanhais nativos da Amazônia. Ciênc. Florest., Santa Maria, 29 (2), 607-621, June. 